\title{
Effectiveness of surgical fixation for rib fractures in relation to its timing: a retrospective Japanese nationwide study
}

\author{
Shunichi Otaka ${ }^{1}$ (D) Shotaro Aso ${ }^{2} \cdot$ Hiroki Matsui ${ }^{1} \cdot$ Kiyohide Fushimi $^{3} \cdot$ Hideo Yasunaga $^{1}$
}

Received: 3 July 2020 / Accepted: 2 November 2020 / Published online: 18 November 2020

(c) Springer-Verlag GmbH Germany, part of Springer Nature 2020, corrected publication 2021

\begin{abstract}
Purpose The effectiveness of surgical rib fixation is currently controversial, partly because of differences in timing. We used a Japanese nationwide database to investigate the effectiveness of surgical rib fixation in relation to its timing.

Methods We used the Japanese Diagnosis Procedure Combination database to identify patients with rib fractures who underwent mechanical ventilation from 1 July 2010 to 31 March 2018. We performed overlap weight analysis to compare in-hospital outcomes between patients who had and had not undergone surgical rib fixation within 3,6 or 10 days after admission. The primary outcomes were duration of mechanical ventilation and post-rib fixation length of hospital stay. The secondary outcomes were tracheostomy, post-admission pneumonia and all-cause 28-day in-hospital mortality.

Results We identified 8922 eligible patients. Surgical rib fixation within 3 days after admission was associated with shorter duration of mechanical ventilation (percent difference, $-42.9 \%$; 95\% confidence interval, -57.4 to -23.3 ) and shorter hospital stay (percent difference, $-19.6 \%$; 95\% confidence interval, -31.8 to -5.2 ). There were no significant differences between the groups in tracheostomy (risk difference, $-0.04 ; 95 \%$ confidence interval, -0.15 to 0.07 ), post-admission pneumonia (risk difference, $-0.04 ; 95 \%$ confidence interval, -0.13 to 0.05 ) or all-cause 28 -day in-hospital mortality (risk difference, -0.02 ; $95 \%$ confidence interval, -0.07 to 0.03 ). However, there were no significant differences in any in-hospital outcomes between those who had and had not undergone rib fixation within 6 or 10 days after admission.

Conclusion Early surgical rib fixation was associated with better in-hospital outcomes, whereas later surgical rib fixation was not.
\end{abstract}

Keywords Rib fracture $\cdot$ Rib fixation · Timing $\cdot$ Overlap weights

Electronic supplementary material The online version of this article (https://doi.org/10.1007/s00068-020-01548-1) contains supplementary material, which is available to authorized users.

Shunichi Otaka

shun-tky@umin.ac.jp

1 Department of Clinical Epidemiology and Health Economics, School of Public Health, The University of Tokyo, 7-3-1 Hongo, Bunkyo-ku, Tokyo 113-0033, Japan

2 Department of Biostatistics and Bioinformatics, The University of Tokyo, Tokyo, Japan

3 Department of Health Policy and Informatics, Tokyo Medical and Dental University Graduate School of Medicine, Tokyo, Japan

\section{Introduction}

Rib fractures are present in 10\%-39\% of all trauma patients $[1,2]$. The symptoms generally do not interfere with daily activities; however, severe pain and chest deformity sometimes restrict thoracic movement and cause respiratory failure. Furthermore, rib fractures are strongly associated with other pulmonary complications such as pneumothorax, hemothorax and pulmonary contusion [3]. Some patients, therefore, require mechanical ventilation $[4,5]$.

Most patients who require mechanical ventilation for the treatment of rib fractures are treated non-operatively with adequate pain control and are discharged without major complications [5]. However, some patients undergo surgical fixation of rib fractures despite its effectiveness being controversial. Some clinicians prefer to adopt a watch-andwait strategy and withhold surgical rib fixation until nonoperative management fails $[6,7]$. 
A systematic review found that surgical rib fixation was associated with shorter duration of mechanical ventilation and lower rates of mortality, post-admission pneumonia, and tracheostomy compared with non-operative management [8]. The studies reviewed had small patient cohorts and the timing of surgical rib fixation varied considerably. A prospective study regarding the timing of surgical rib fixation reported that early surgical rib fixation resulted in shorter lengths of hospital and intensive care unit stays than did late surgical rib fixation [9]. However, that study did not fully adjust for patients' characteristics and there may have been selection biases.

In this study, we compared in-hospital outcomes (length of hospital stay and duration of mechanical ventilation) between patients who did and did not undergo surgical rib fixation. We hypothesized that early surgical rib fixation is associated with better in-hospital outcomes than nonoperative management and that late surgical rib fixation is less effective than earlier fixation.

\section{Materials and methods}

\section{Study design and setting}

We extracted data from the Diagnosis Procedure Combination inpatient database in Japan. The details of this database have been described elsewhere [10]. Briefly, the database includes hospital discharge and administrative claims data for more than 1100 acute care hospitals and covers up to $80 \%$ of all inpatient admissions to tertiarycare emergency hospitals in Japan. The database includes the following individual information: age, sex, body weight, height, dates of admission and discharge, admission diagnoses, comorbidities on admission, complications during hospitalization, procedures such as surgical rib fixation, tracheostomy, mechanical ventilation, chest drainage, drugs, intensive care unit admission and discharge status. Diagnoses, comorbidities and complications are recorded according to the International Classification of Diseases, 10th Revision (ICD-10) codes. A previous study has validated the records of diagnoses and procedures in the Diagnosis Procedure Combination data [11]. That study reported that the sensitivity of the diagnoses ranged from 30 to $80 \%$ and the specificity of the diagnoses exceeded $96 \%$. The sensitivity and the specificity of the records of procedures exceeded $90 \%$. This study was approved by the institutional Review Board of The University of Tokyo [approved number: 3501-(3) (25 December 2017)]. Because we used only anonymized data, the requirement for consent was waived.

\section{Patient selection}

We used patients' data from the Diagnosis Procedure Combination database from 1 July 2010 to 31 March 2018. We included patients who met all the following criteria: (I) admitted with rib fractures (ICD-10 codes; S22.3-S22.5) and (II) required mechanical ventilation within 1 day after admission. We excluded the following patients: (I) extubated before surgical rib fixation or (II) died before the designated day (3, 6 or 10 days after admission; details provided in next section).

\section{Variables and outcomes}

We collected the following variables: age (years), sex, body mass index (BMI), Japan Coma Scale score on admission, comorbidities on admission, procedures on admission (catecholamine use, chest drainage, transfusion and transarterial embolization), intervention for other organs (craniotomy, thoracotomy, laparotomy, spinal fusion, pelvic open reduction and internal fixation (ORIF), surgery to limbs), Charlson Comorbidity Index [12], ICD10-based severity scores for trauma, and admission to the intensive care unit. We classified age into four categories: $<60,60-69,70-79$ and $\geq 80$ years and BMI into four categories: $<18.5,18.5-24.9,25.0-29.9$ and $\geq 30 \mathrm{~kg} / \mathrm{m}^{2}$.

We used Japan Coma Scale scores to classify the level of a patient's consciousness [13-15]. Japan Coma Scale scores are widely used in Japan. There are four categories: 0 (alert and conscious), 1-3 (drowsy, but awake without stimulation), 10-30 (lethargic and drowsy, but can be aroused with stimulation) and 100-300 (coma). Japan Coma Scale scores correlate well with Glasgow Coma Scale scores [14].

We included the following comorbidities on the basis of ICD-10 codes: clinically important traumatic brain injury (S02.0, 02.1, 02.9, 04.x, 06.x), cervical fracture (S12.0, $12.1,12.2,12.2,12.7,12.9)$, vertebral fracture (S22.0, 22.1, 32.0, 32.1, T02.1, T08), clavicular fracture (S42.0), sternal fracture (S22.2), scapular fracture (S42.1), flail chest (S22.5) and pelvic fracture (S32.0, 32.3, 32.4, 32.5, $32.7,32.8)$.

We used ICD-10-based severity scores for trauma to adjust for trauma severity. This score has been validated and shown to predict in-hospital mortality accurately [16].

The study outcomes were duration of mechanical ventilation, length of hospital stay, proportion of patients requiring tracheostomy, proportion of patients developing pneumonia after admission and all-cause 28-day in-hospital mortality.

Because we hypothesized that the effectiveness of surgical rib fixation may vary according to its timing, we 
compared outcomes between patients who underwent surgical rib fixation from 1 to 3 days (within 3 days), 1 to 6 days (within 6 days) or 1 to 10 days (within 10 days) after admission (treated group) and those who did not undergo surgical rib fixation within the designated time period (untreated group).

\section{Statistical analysis}

We used propensity score analysis to compare outcomes between the groups. We used multivariable logistic regression model to determine propensity scores for surgical rib fixation within 3, 6 or 10 days after admission. We included the following independent variables in the model: age, sex, BMI, Japan Coma Scale scores on admission, clinically important traumatic brain injury, cervical fracture, vertebral fracture, clavicular fracture, sternal fracture, scapular fracture, flail chest, pelvic fracture, catecholamine use, chest drainage, transfusion, transarterial embolization, craniotomy, thoracotomy, laparotomy, pelvic ORIF, surgery to limbs, Charlson Comorbidity Index and ICD-10-based severity score for trauma. To discriminate the model, we evaluated the C-statistic. We assessed differences in patients' characteristics between the groups using standardized differences. We regarded standardized difference of $>0.1$ as meaningful imbalances [17].

We used the "overlap weights" method to compare the groups because there were substantial differences between them and some extremely high or low propensity scores $[18$, 19].

Overlap weights has recently been introduced as a propensity score weighting method. Details of this method are described elsewhere [20]. With this method, the weight is defined as 1 -propensity score for treated patient and propensity score for untreated patient. Therefore, the maximum weight on the propensity score is 0.5 , this score being of the greatest interest, whereas less emphasis is placed on extremely high or low propensity scores (approaching 0 or $1)$.

The overlap weights method has several advantages. There is no need to trim and discard patients, whereas several other weighting methods sometimes require trimming if there are extreme propensity scores. In overlap weights, all weights fall between 0 and 1 , whereas in some other statistical methods such as "conventional inverse propensity score weighting", the weights have no upper boundary. The overlap weights method therefore eliminates the potential bias that can arise from multiplication of scores of the few patients with extremely high or low propensity scores. Furthermore, one study has shown that overlap weights may be more efficient than inverse probability of treatment weighting and propensity score with trimming [20].
We divided the patients into three arms: (1) patients who underwent surgical rib fixation within 3 days after admission or not, excluding those who died within 3 days after admission; (2) patients who underwent surgical rib fixation within 6 days after admission or not, excluding those who died within 6 days after admission and (3) patients who underwent surgical rib fixation within 10 days after admission or not, excluding those who died within 10 days after admission.

The primary outcomes were the duration of mechanical ventilation and the length of hospital stay. The secondary outcomes were the proportion of patients requiring tracheostomy, the incidence of post-admission pneumonia, and the all-cause 28-day in-hospital mortality rate. To analyze continuous outcomes, we changed the continuous variables into natural logarithms to satisfy the homoscedasticity condition for linear regression. We estimated percent differences and their $95 \%$ confidence interval (CI) by $\exp (\beta)-1$, where $\beta$ denotes the coefficients of the linear regression models. In the unadjusted analyses, we used Student's $t$ test for continuous variables and the $\chi^{2}$ test or Fisher's exact test for categorical variables.

We performed several sensitivity analyses. First, we analyzed the duration of mechanical ventilation and the length of hospital stay in both groups without transforming these values into natural logarithms. Second, we compared the outcomes after excluding patients with clinically important traumatic brain injury, cervical fracture, craniotomy on admission, and spinal fusion on admission. Third, we compared the outcomes among patients without flail chest.

We have expressed continuous variables as mean and standard deviation or medians and interquartile ranges and categorical variables as frequencies and percentages. All $p$ values are two sided, and we considered $p$ values $<0.05$ to denote statistical significance. We performed all statistical analyses using the general statistical package STATA, version 16.0 (Stata Corporation, College Station, TX, USA).

\section{Results}

We identified 8940 patients who were admitted to hospitals, diagnosed with rib fractures and underwent mechanical ventilation within 1 day after admission. Figure 1 shows the flow of the patients. We excluded 18 patients who were extubated before surgical rib fixation, leaving 8922 eligible patients.

\section{Surgical rib fixation within 3 days after admission or not}

We excluded 2607 patients because they died within 3 days after admission. This left 62 patients in the treated group 
Fig.1 Patient selection flowchart

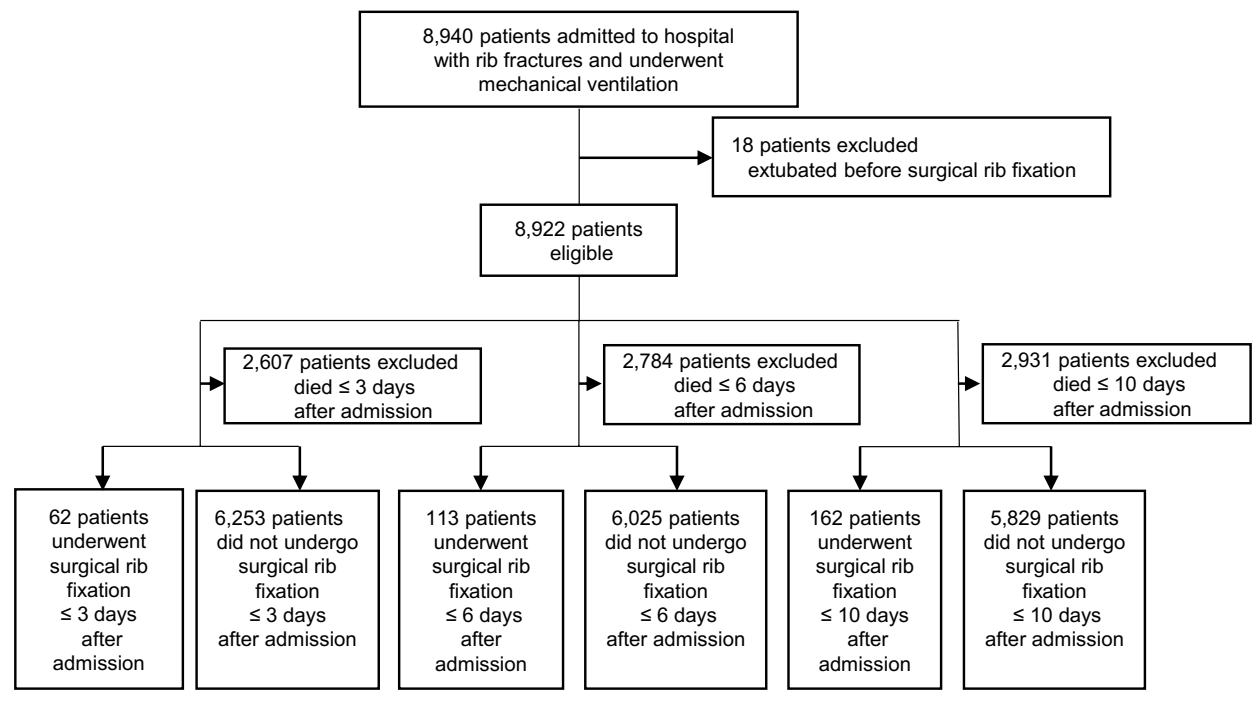

and 6253 in the untreated group. The treated group was older, had higher BMIs, higher proportions of alert conscious state, clavicular fractures, sternal fractures, scapular fractures, flail chest, catecholamine use, chest drainage, transfusion, thoracotomy, pelvic ORIF, surgery to limbs and smaller proportions of clinically important traumatic brain injury, transarterial embolization, craniotomy, laparotomy, spinal fusion and lower Charlson Comorbidity Index scores (Table 1). In the unadjusted analysis, patients who underwent surgical rib fixation had a shorter length of hospital stay (32.1 vs. 45.1 days; difference, 13.0 days; 95\% CI 1.3-24.6; $p=0.03$ ). We found no significant differences between the groups in the duration of mechanical ventilation ( 7.3 vs. 13.4 days; difference, 6.1 days; $95 \%$ CI -0.1 to $12.3 ; p=0.05$ ), proportion of patients undergoing tracheostomy (19.4 vs. $25.6 \% ; p=0.26)$, incidence of post-admission pneumonia ( 11.3 vs. $18.5 \% ; p=0.14)$ or all-cause 28 -day in-hospital mortality rate (3.2 vs. $9.1 \%$; $p=0.11$ ).

The C-statistic of the propensity score was 0.87 . After overlap weighting, there were no imbalances between the groups (Table1). Tables 2 and 3 show the results of the analysis. In the adjusted analysis, patients who underwent surgical rib fixation within 3 days after admission showed shorter duration of mechanical ventilation (percent difference, $-42.9 \%$; $95 \% \mathrm{CI}-57.4$ to $-23.3 ; p<0.001$ ) and shorter length of hospital stay (percent difference, $-19.6 \%$; $95 \% \mathrm{CI}-31.8$ to $-5.2 ; p=0.009$ ) than those who did not. We found no significant differences between the groups in the proportions of tracheostomy (risk difference, -0.04 ; $95 \% \mathrm{CI}-0.15$ to $0.07 ; p=0.43$ ), post-admission pneumonia (risk difference, -0.04 ; $95 \% \mathrm{CI}-0.13$ to 0.05 ; $p=0.35$ ) and all-cause 28-day in-hospital mortality (risk difference, $-0.02 ; 95 \% \mathrm{CI}-0.07$ to $0.03 ; p=0.40$ ).

\section{Surgical rib fixation within 6 days after admission or not}

We excluded 2784 patients because they died within 6 days after admission. This left 113 patients in the treated group and 6025 in the untreated group. We calculated the propensity scores; the C-statistic of the propensity score was 0.82 . After overlap weighting, there were no imbalances between the groups (Online Resource 1). In the adjusted analysis, there were no significant differences between the groups in duration of mechanical ventilation, length of hospital stay, tracheostomy, proportion of post-admission pneumonia and all-cause 28-day in-hospital mortality (Online Resources 2 and 3 ).

\section{Surgical rib fixation within 10 days after admission or not}

We excluded 2931 patients because they died within 10 days after admission. This left 162 patients in the treated group and 5829 in the untreated group. We calculated the C-statistic of the propensity score as 0.80 . After overlap weighting, there were no imbalances between the groups (Online Resource 4). In the adjusted analysis, the results were similar to those for patients treated within 6 days (Online Resources 5 and 6 ).

\section{Sensitivity analyses}

We performed several sensitivity analyses. The results are shown in Online Resources 7-21. The results were similar to those of the main analyses. 
Table 1 Patient characteristics according to surgical rib fixation status within 3 days after admission in the original and overlap weights adjusted cohorts

\begin{tabular}{|c|c|c|c|c|c|c|}
\hline & $\begin{array}{l}\text { Patients who did not } \\
\text { undergo surgical rib } \\
\text { fixation } \leq 3 \text { days after } \\
\text { admission }(n=6253)\end{array}$ & $\begin{array}{l}\text { Patients who } \\
\text { underwent } \\
\text { surgical rib } \\
\text { fixation } \leq 3 \text { days } \\
\text { after admission } \\
(n=62)\end{array}$ & $\begin{array}{l}\text { Standardized } \\
\text { difference (\%) }\end{array}$ & $\begin{array}{l}\text { Patients who did not } \\
\text { undergo surgical rib } \\
\text { fixation } \leq 3 \text { days after } \\
\text { admission }(n=6253)\end{array}$ & $\begin{array}{l}\text { Patients who under- } \\
\text { went surgical rib } \\
\text { fixation } \leq 3 \text { days after } \\
\text { admission }(n=62)\end{array}$ & $\begin{array}{l}\text { Standardized } \\
\text { difference } \\
(\%)\end{array}$ \\
\hline $\begin{array}{l}\text { Age: years, mean } \\
\text { (SD) }\end{array}$ & $64.1(19.8)$ & $66.6(14.6)$ & & 65.9 & 66.9 & \\
\hline \multicolumn{3}{|l|}{ Age groups: years, $n(\%)$} & 31.5 & & & \\
\hline$<60$ & $2024(32.4)$ & $14(22.6)$ & & $(23.2)$ & $(23.2)$ & 0.0 \\
\hline $60-69$ & $1199(19.2)$ & $17(27.4)$ & & $(25.3)$ & $(25.3)$ & 0.0 \\
\hline $70-79$ & $1571(25.1)$ & $20(32.3)$ & & $(32.0)$ & $(32.0)$ & 0.0 \\
\hline $80 \leq$ & $1459(23.3)$ & $11(17.7)$ & & $(19.5)$ & $(19.5)$ & 0.0 \\
\hline Sex (male), $n(\%)$ & $4067(65.0)$ & $41(66.1)$ & 2.3 & $(64.0)$ & $(64.0)$ & 0.0 \\
\hline $\begin{array}{l}\text { Body mass index: kg/ } \\
\mathrm{m}^{2} \text {, mean (SD) }\end{array}$ & $22.5(4.9)$ & $23.4(4.8)$ & & 22.9 & 23.4 & \\
\hline \multicolumn{3}{|c|}{ Body mass index groups: $\mathrm{kg} / \mathrm{m}^{2}, n(\%)$} & 27.1 & & & \\
\hline$<18.5$ & $799(12.8)$ & $9(14.5)$ & & $(15.2)$ & $(15.2)$ & 0.0 \\
\hline $18.5-24.9$ & $3373(53.9)$ & $33(53.2)$ & & $(55.4)$ & $(55.4)$ & 0.0 \\
\hline $25-29.9$ & $1193(19.1)$ & $12(19.4)$ & & $(21.3)$ & $(21.3)$ & 0.0 \\
\hline $30 \leq$ & $241(3.9)$ & $5(8.1)$ & & $(8.2)$ & $(8.2)$ & 0.0 \\
\hline Missing & $647(10.4)$ & $3(4.8)$ & & & & \\
\hline \multicolumn{3}{|l|}{ Japan Coma Scale, $n(\%)$} & 71.7 & & & \\
\hline 0 (alert) & $1756(28.1)$ & $38(61.3)$ & & $(59.6)$ & $(59.6)$ & 0.0 \\
\hline 1-3 (dizziness) & $1392(22.3)$ & $9(14.5)$ & & $(14.2)$ & $(14.2)$ & 0.0 \\
\hline 10-30 (somnolence) & $979(15.7)$ & $5(8.1)$ & & (8.6) & $(8.6)$ & 0.0 \\
\hline 100-300 (coma) & $2126(34.0)$ & $10(16.1)$ & & $(17.5)$ & $(17.5)$ & 0.0 \\
\hline \multicolumn{7}{|l|}{ Comorbidities, $n(\%)$} \\
\hline $\begin{array}{l}\text { Clinically important } \\
\text { traumatic brain } \\
\text { injury }\end{array}$ & $1426(22.8)$ & $10(16.1)$ & 16.9 & $(15.3)$ & $(15.3)$ & 0.0 \\
\hline Cervical fracture & $264(4.2)$ & $2(3.2)$ & 5.3 & (3.4) & $(3.4)$ & 0.0 \\
\hline Vertebral fracture & $683(10.9)$ & $6(9.7)$ & 4.1 & $(10.2)$ & $(10.2)$ & 0.0 \\
\hline Clavicular fracture & $579(9.3)$ & $9(14.5)$ & 16.3 & $(13.6)$ & $(13.6)$ & 0.0 \\
\hline Sternal fracture & $170(2.7)$ & $4(6.5)$ & 17.9 & $(6.8)$ & $(6.8)$ & 0.0 \\
\hline Scapular fracture & $289(4.6)$ & $5(8.1)$ & 14.2 & $(8.5)$ & $(8.5)$ & 0.0 \\
\hline Flail chest & $228(3.6)$ & $11(17.7)$ & 46.8 & $(15.4)$ & $(15.4)$ & 0.0 \\
\hline Pelvic fracture & $784(12.5)$ & $8(12.9)$ & 1.1 & $(11.8)$ & $(11.8)$ & 0.0 \\
\hline \multicolumn{7}{|c|}{ Procedures on admission, $n(\%)$} \\
\hline Catecholamine use & $3153(50.4)$ & $40(64.5)$ & 28.8 & $(63.5)$ & $(63.5)$ & 0.0 \\
\hline Chest drainage & $2400(38.4)$ & $27(43.5)$ & 10.5 & $(45.4)$ & $(45.4)$ & 0.0 \\
\hline Transfusion & $312(54.6)$ & $45(72.6)$ & 38.1 & $(72.7)$ & $(72.7)$ & 0.0 \\
\hline $\begin{array}{l}\text { Transarterial embo- } \\
\text { lization }\end{array}$ & $1016(16.2)$ & $3(4.8)$ & 37.8 & $(5.2)$ & $(5.2)$ & 0.0 \\
\hline \multicolumn{7}{|c|}{ Interventions for other organs, $n(\%)$} \\
\hline Craniotomy & $524(8.2)$ & $1(1.6)$ & 31.4 & $(1.8)$ & $(1.8)$ & 0.0 \\
\hline Thoracotomy & 285 (4.6) & $17(27.4)$ & 65.7 & $(27.3)$ & $(27.3)$ & 0.0 \\
\hline Laparotomy & $413(6.6)$ & $2(3.2)$ & 15.7 & (3.6) & $(3.6)$ & 0.0 \\
\hline Spinal fusion & $125(2.0)$ & $0(0.0)$ & 20.2 & & & \\
\hline Pelvic ORIF & $207(3.3)$ & $6(9.7)$ & 26.1 & $(8.4)$ & $(8.4)$ & 0.0 \\
\hline Surgery to limbs & $587(9.4)$ & $13(21.0)$ & 32.7 & $(20.3)$ & $(20.3)$ & 0.0 \\
\hline \multicolumn{3}{|c|}{ Charlson Comorbidity Index, $n(\%)$} & 37.0 & & & \\
\hline
\end{tabular}


Table 1 (continued)

\begin{tabular}{|c|c|c|c|c|c|c|}
\hline & $\begin{array}{l}\text { Patients who did not } \\
\text { undergo surgical rib } \\
\text { fixation } \leq 3 \text { days after } \\
\text { admission }(n=6253)\end{array}$ & $\begin{array}{l}\text { Patients who } \\
\text { underwent } \\
\text { surgical rib } \\
\text { fixation } \leq 3 \text { days } \\
\text { after admission } \\
(n=62)\end{array}$ & $\begin{array}{l}\text { Standardized } \\
\text { difference }(\%)\end{array}$ & $\begin{array}{l}\text { Patients who did not } \\
\text { undergo surgical rib } \\
\text { fixation } \leq 3 \text { days after } \\
\text { admission }(n=6253)\end{array}$ & $\begin{array}{l}\text { Patients who under- } \\
\text { went surgical rib } \\
\text { fixation } \leq 3 \text { days after } \\
\text { admission }(n=62)\end{array}$ & $\begin{array}{l}\text { Standardized } \\
\text { difference } \\
(\%)\end{array}$ \\
\hline 0 & $4802(76.8)$ & $55(88.7)$ & & $(88.0)$ & $(88.0)$ & 0.0 \\
\hline 1 & $967(15.5)$ & $4(6.5)$ & & $(6.9)$ & $(6.9)$ & 0.0 \\
\hline 2 & $331(5.3)$ & $1(1.6)$ & & $(1.8)$ & $(1.8)$ & 0.0 \\
\hline $3 \leq$ & $153(2.4)$ & $2(3.2)$ & & $(3.3)$ & (3.3) & 0.0 \\
\hline $\begin{array}{l}\text { ICD-10-based sever- } \\
\text { ity score for trauma, } \\
\text { mean (SD) }\end{array}$ & $9.1(6.3)$ & $9.2(4.5)$ & 2.7 & 8.9 & 8.9 & 0.0 \\
\hline ICU admission $n,(\%)$ & $5584(89.3)$ & $56(90.3)$ & 3.4 & $(89.6)$ & $(89.6)$ & 0.0 \\
\hline
\end{tabular}

ICD International Classification of Diseases, ICU intensive care unit, ORIF open reduction and internal fixation, $S D$ standard deviation

Table 2 Duration of mechanical ventilation and length of hospital according to surgical rib fixation status within 3 days after admission adjusted using overlap weights

\begin{tabular}{llll}
\hline Variables & $\begin{array}{l}\text { Percent differ- } \\
\text { ence }(\%)\end{array}$ & 95\% confidence interval & $p$ value \\
\hline $\begin{array}{c}\text { Duration of } \\
\text { mechanical }\end{array}$ & -42.9 & -57.4 to -23.3 & $<0.001$ \\
$\begin{array}{c}\text { ventilation } \\
\text { Length of hos- } \\
\text { pital stay }\end{array}$ & -19.6 & -31.8 to -5.2 & 0.009 \\
\hline
\end{tabular}

\section{Discussion}

We used data from a Japanese nationwide database to investigate in-hospital outcomes in relation to the timing of surgical rib fixation with adjustment for patients' characteristics, comorbidities, procedures and severity. Our analyses showed that patients who underwent surgical rib fixation within 3 days after admission had a shorter duration of mechanical ventilation and shorter length of hospital stay than did those who had not. However, there were no significant differences in any in-hospital outcomes between those who had and had not undergone surgical rib fixation within 6 or 10 days after admission.
Previous studies have shown conflicting results on in-hospital outcomes after surgical rib fixation, partly because of variations in its timing [21-23]. Few studies have compared early and late surgical rib fixation $[9,24]$. To the best of our knowledge, this is the first study to compare the outcomes of surgical rib fixation in relation to the interval between admission and surgery. After adjusting for patients' characteristics using overlap weights, we found that the effectiveness of surgical rib fixation compared with non-operative management depended on the timing of the surgical fixation.

In the present study, we found that earlier surgical rib fixation was associated with shorter duration of mechanical ventilation and shorter length of hospital stay compared with non-operative management within 3 days after admission, whereas there was no such association for later surgical rib fixation. These results are biologically plausible. Surgical rib fixation stabilizes movement of the rib fragments, which decreases pain and enables the rib cage to move efficiently, thus facilitating early rehabilitation. However, patients who undergo surgical rib fixation later are mechanically ventilated for longer, which may weaken their respiratory muscles. Therefore, even after surgical rib fixation, it takes time to wean them off a ventilator. Thus, delayed surgical rib fixation could be less effective than not undergoing rib fixation at all.

Table 3 Proportion of tracheostomy, post-admission pneumonia and all-cause 28-day in-hospital mortality according to surgical rib fixation status within 3 days after admission adjusted using overlap weights

\begin{tabular}{llllll}
\hline Variables & Treated group & Untreated group & Risk difference & 95\% confidence interval & $p$ value \\
\hline Tracheostomy & 0.21 & 0.26 & -0.04 & -0.15 to 0.07 & 0.43 \\
Pneumonia after admission & 0.12 & 0.16 & -0.04 & -0.13 to 0.05 & 0.35 \\
All-cause 28-day in-hospital mortality & 0.03 & 0.06 & -0.02 & -0.07 to 0.03 & 0.40 \\
\hline
\end{tabular}


This study has several limitations. First, we could not obtain detailed information about the rib fractures. However, the usefulness of information on the number and location of rib fractures and RibScores has not been well studied [25-27]. Second, the indications of surgical rib fixation may have differed between the participating hospitals and doctors because these indications remain controversial $[28,29]$. Third, the effectiveness of surgical rib fixation for patients with mild injury was unknown because we excluded those who were extubated before rib fixation. Fourth, patients who underwent early surgical rib fixation showed better outcomes than those who did not; however, the most appropriate timing of surgical fixation for rib fracture remains unknown. Fifth, this study included a small number of patients.

In conclusion, we performed overlap weights analysis using data of a Japanese nationwide cohort of patients with rib fractures to compare in-hospital outcomes between patients who did and did not undergo surgical rib fixation within 3,6 or 10 days after admission. Surgical rib fixation within 3 days after admission was associated with a reduction in duration of mechanical ventilation and length of hospital stay. However, these benefits may decrease as surgery is delayed. We recommend that surgical fixation for rib fractures is performed as early as possible to maximize the benefits to patients.

Author contributions Conceptualization: SO, SA, and HY; methodology: SO, SA, HM, and HY; formal analysis and investigation: SO, SA, and $\mathrm{HY}$; writing - original draft preparation: SO and SA; writingreview and editing: SO, SA, and $\mathrm{HY}$; funding acquisition: $\mathrm{KF}$ and $\mathrm{HY}$; resources: $\mathrm{HM}, \mathrm{KF}$, and $\mathrm{HY}$; supervision: SA, HM, KF, and HY. All authors read and approved the final manuscript.

Funding Kiyohide Fushimi is currently receiving a grant (H30-Policy-Designated-004) from the Ministry of Education, Culture, Sports, Science and Technology, Japan. Hideo Yasunaga is currently receiving grants (19AA2007 and 20AA2005) from the Ministry of Health, Labour and Welfare, Japan and a grant (20H03907) from the Ministry of Education, Culture, Sports, Science and Technology, Japan. For the remaining authors, none were declared.

Availability of data and material/code availability The datasets analyzed during the current study are not publicly available due to contracts with the hospitals providing data to the database.

\section{Compliance with ethical standards}

Conflict of interest The authors declare that they have no conflicts of interest.

Ethics approval This is an observational study. This study was approved by the institutional Review Board of The University of Tokyo [approved number: 3501-(3) (25 December 2017)].

Consent to participate Because we used only anonymized data, the requirement for consent was waived.

\section{References}

1. Ziegler DW, Agarwal NN. The morbidity and mortality of rib fractures. J Trauma. 1994;37:975-9.

2. Lafferty PM, Anavian J, Will RE, Cole PA. Operative treatment of chest wall injuries: indications, technique, and outcomes. J Bone Jt Surg Am. 2011;93:97-110.

3. Sırmalı M, Türüt H, Topçu S, Gülhan E, Lkü Yazıcı Ü, Kaya $\mathrm{S}$, et al. A comprehensive analysis of traumatic rib fractures: morbidity, mortality and management. Eur J Cadiothorac Surg. 2003;24:133-8.

4. Ahn Y, Görlinger K, Alam HB, Eikermann M. Pain-associated respiratory failure in chest trauma. Anesthesiology. 2013;118:701-8.

5. Dehghan N, de Mestral C, McKee MD, Schemitsch EH, Nathens A. Flail chest injuries: a review of outcomes and treatment practices from the National Trauma Data Bank. J Trauma Acute Care Surg. 2014;76:462-8.

6. Doben AR, Eriksson EA, Denlinger CE, Leon SM, Couillard DJ, Fakhry SM, et al. Surgical rib fixation for flail chest deformity improves liberation from mechanical ventilation. J Crit Care. 2014;29:139-43.

7. Mayberry JC, Ham LB, Schipper PH, Ellis TJ, Mullins RJ. Surveyed opinion of American trauma, orthopedic, and thoracic surgeons on rib and sternal fracture repair. J Trauma. 2009;66:875-9.

8. Liu X, Xiong K. Surgical management versus non-surgical management of rib fractures in chest trauma: a systematic review and meta-analysis. J Cardiothorac Surg. 2019;14:45.

9. Pieracci FM, Coleman J, Ali-Osman F, Mangram A, Majercik S, White TW, et al. A multicenter evaluation of the optimal timing of surgical stabilization of rib fractures. J Trauma Acute Care Surg. 2018;84:1-10.

10. Yasunaga H, Matsui H, Horiguchi H, Fushimi K, Matsuda S. Clinical epidemiology and health services research using the Diagnosis Procedure Combination Database in Japan. Asian Pacific J Dis Manag. 2015;7:19-24.

11. Yamana H, Moriwaki M, Horiguchi H, Kodan M, Fushimi $\mathrm{K}$, Yasunaga $\mathrm{H}$. Validity of diagnoses, procedures, and laboratory data in Japanese administrative data. J Epidemiol. 2017;27:476-82.

12. Sundararajan V, Henderson T, Perry C, Muggivan A, Quan H, Ghali WA. New ICD-10 version of the Charlson comorbidity index predicted in-hospital mortality. J Clin Epidemiol. 2004;57:1288-94.

13. Ohta T, Waga S, Handa H, Saito I, Takeuchi K, Suzuki JTA. New grading of level of disordered consciousness (author's translation). No Shinkei Geka. 1974;2:623-7.

14. Ono K, Wada K, Takahara T, Shirotani T. Indications for computed tomography in patients with mild head injury. Neurol Med Chir (Tokyo). 2007;47:291-7.

15. Shigematsu K, Nakano H, Watanabe Y. The eye response test alone is sufficient to predict stroke outcome-reintroduction of Japan Coma Scale: a cohort study. BMJ Open. 2013;3:e002736.

16. Wada T, Yasunaga H, Yamana H, Matsui H, Matsubara T, Fushimi K, et al. Development and validation of a new ICD-10-based trauma mortality prediction scoring system using a Japanese national inpatient database. Inj Prev. 2017;23:263-7.

17. Austin PC. Balance diagnostics for comparing the distribution of baseline covariates between treatment groups in propensity-score matched samples. Stat Med. 2009;28:3083-107.

18. Li F, Morgan KL, Zaslavsky AM. Balancing covariates via propensity score weighting. J Am Stat Assoc. 2018;113:390-400.

19. Mlcoch T, Hrnciarova T, Tuzil J, Zadak J, Marian M, Dolezal T. Propensity score weighting using overlap weights: a new method applied to regorafenib clinical data and a cost-effectiveness analysis. Value Health. 2019;22:1370-7. 
20. Li F, Thomas LE. Addressing extreme propensity scores via the overlap weights. Am J Epidemiol. 2019;188:250-7.

21. Farquhar J, Almahrabi Y, Slobogean G, Slobogean B, Garraway N, Simons RK, et al. No benefit to surgical fixation of flail chest injuries compared with modern comprehensive management: results of a retrospective cohort study. Can J Surg. 2016;59:299-303.

22. Marasco SF, Davies AR, Cooper J, Varma D, Bennett V, Nevill R, et al. Prospective randomized controlled trial of operative rib fixation in traumatic flail chest. J Am Coll Surg. 2013;216:924-32.

23. Shibahashi K, Sugiyama K, Okura Y, Hamabe Y. Effect of surgical rib fixation for rib fracture on mortality: a multicenter, propensity score matching analysis. J Trauma Acute Care Surg. 2019;87:599-605.

24. Su Y-H, Yang S-M, Huang C-H, Ko H-J. Early versus late surgical stabilization of severe rib fractures in patients with respiratory failure: a retrospective study. PLoS ONE. 2019;14:e0216170.

25. Shulzhenko NO, Zens TJ, Beems MV, Jung HS, O'Rourke AP, Liepert AE, et al. Number of rib fractures thresholds independently predict worse outcomes in older patients with blunt trauma. Surgery. 2017;161:1083-9.

26. Whitson BA, McGonigal MD, Anderson CP, Dries DJ. Increasing numbers of rib fractures do not worsen outcome: an analysis of the national trauma data bank. Am Surg. 2013;79:140-50.

27. Chapman BC, Herbert B, Rodil M, Salotto J, Stovall RT, Biffl W, et al. RibScore: a novel radiographic score based on fracture pattern that predicts pneumonia, respiratory failure, and tracheostomy. J Trauma Acute Care Surg. 2016;80:95-101.

28. Uchida K, Nishimura T, Takesada H, Morioka T, Hagawa N, Yamamoto T, et al. Evaluation of efficacy and indications of surgical fixation for multiple rib fractures: a propensity-score matched analysis. Eur J Trauma Emerg Surg. 2017;43:541-7.

29. Brasel KJ, Moore EE, Albrecht RA, deMoya M, Schreiber M, Karmy-Jones R, et al. Western Trauma Association critical decisions in trauma. J Trauma Acute Care Surg. 2017;82:200-3. 